\title{
O protagonismo na linguagem na mediação familiar judicial ${ }^{1}$
}

\section{Protagonism in language in judicial familiar mediation}

\author{
Paulo Cortes Gago* \\ Universidade Federal do Rio de Janeiro \\ Rio de Janeiro, Rio de Janeiro / Brasil \\ Priscila Fernandes Sant'Anna** \\ Universidade Federal de Juiz de Fora \\ Juiz de Fora, Minas Gerais / Brasil
}

\begin{abstract}
RESUMO: Este artigo analisa, no âmbito da Linguística Aplicada e em uma perspectiva interacional, a fase denominada "historiando o conflito", uma das cinco fases identificadas pelo grupo de pesquisa Interação em Contextos Institucionais como recorrentes em uma entrevista de mediação. Este trabalho analisa como o mediador e as partes em desacordo negociam os espaços para que o conflito possa ser elaborado, trabalhado e transformado por aqueles que procuram a Justiça para resolverem suas questões familiares. A análise de dados reais de fala-em-interação mostra que a formulação, a reformulação e a coconstrução das narrativas são a forma central de ação dos atores no contexto estudado, sendo a construção de suas identidades realizada por meio da linguagem. Por fim, tal como postulam os manuais do direito e por meio do estudo das narrativas, analisamos o empoderamento e o exercício de protagonismo por parte dos entrevistados.
\end{abstract}

PALAVRAS-CHAVE: mediação; fala-em-interação; narrativas; conflito; empoderamento.

\begin{abstract}
This article analyzes, in the scope of Applied Linguistics and in an interactional perspective, the phase called "Historicizing the Conflict", one of the five phases identified by the research group Interaça em Contextos Institucionais as recurrent in a mediation interview. This research analyses how the mediator and the parties in disagreement negotiate the spaces so that the conflict can be elaborated, worked through and transformed by those who seek
\end{abstract}

\footnotetext{
* pcgago@letras.ufrj.br

** priscila_1803@hotmail.com

${ }^{1}$ Este artigo liga-se à bolsa de produtividade de pesquisa CNPq 311057/2015-2 do primeiro autor.
} 
justice to solve their family issues. The analysis of real talk-in-interaction data shows that formulation, reformulation and co-construction of narratives are the main means of the action of those involved in the context studied, and the identity construction of these actors is accomplished through language. Lastly, as well as the manuals of law postulate and through the study of narratives, we analyzed the empowerment and the exercise of protagonism of the interviewees.

KEYWORDS: mediation; talk-in-interaction; narratives; conflict; empowerment.

\section{Introdução}

Este artigo analisa, no âmbito da Linguística Aplicada e em uma perspectiva interacional, as fases da entrevista de mediação, discutindo como o mediador e as partes em desacordo negociam os espaços para que o conflito possa ser elaborado, trabalhado e transformado por aqueles que procuram a Justiça para tratarem de problemas familiares.

Neste trabalho, em que buscamos refletir sobre a agentividade/ protagonismo dos participantes em uma situação real de fala-em-interação, apresentamos a análise da fase denominada "historiando o conflito", momento da interação que julgamos oportuno para pensarmos o protagonismo/agentividade, por meio da construção conjunta das narrativas ali realizadas.

A mediação, a partir da Lei no 13.140, de 26 de junho de 2015, foi regulamentada como meio obrigatório de resolução de conflitos, exercido por uma terceira parte neutra em relação à controvérsia e capaz de facilitar o diálogo entre as partes. No Brasil, contudo, formas alternativas de resolução de conflito já vêm sendo utilizadas pela sociedade há pelo menos vinte anos, para que questões de diversas ordens possam ser resolvidas de modo mais ágil e consensual, desobstruindo o sistema judiciário brasileiro, extremamente moroso. Experiências como as do Programa de Proteção e Defesa do Consumidor (PROCON) demonstraram que, por meio do diálogo e da negociação entre o consumidor e o prestador de serviço, os usufrutuários de bens e serviços conseguem requerer seus direitos e chegar a acordos satisfatórios em suas trocas comerciais, o que ratifica a importância dessas formas alternativas para atender às necessidades da sociedade brasileira.

No âmbito da mediação familiar judicial, de maneira diferente do contexto anteriormente citado, as relações não se restringem ao tópico em conflito, e, pelo contrário, são permanentes, envolvendo sentimentos, 
histórias compartilhadas, projetos, bens comuns, e, sobretudo, filhos. Dessa forma, quando procuram a mediação para a resolução de um evento envolvendo essas complexidades, as partes apresentam em suas falas, na maioria das vezes, posições diferentes (e frequentemente opostas) sobre um mesmo objeto, razão pela qual essa "anatomia" comunicacional integra a área de fala de conflito (GRIMSHAW, 1990), que possui contornos específicos. Basicamente, um conflito estabelece-se toda vez que há uma posição emanada pelo participante A em um turno de fala (T1); ${ }^{2}$ uma posição divergente é emitida por um segundo participante, em um turno seguinte (T2); e, em um terceiro turno de fala (T3), a oposição é mantida. A continuação desse padrão permite-nos postular a ideia de um escalonamento do conflito.

Em nossa pesquisa encontramos cinco fases da entrevista de mediação com base em um caso de Pedido de Guarda, no âmbito da Vara da Família. Para este artigo, escolhemos discutir a fase denominada "historiando o conflito", visto que, nela, as emoções dos participantes, suas angústias e preocupações vêm à tona, demonstrando momentos em que os participantes assumem o protagonismo em sua própria vida em busca do acordo.

\section{Referenciais teóricos}

A discussão teórica construída neste trabalho ampara-se no arcabouço da Linguística Aplicada de cunho interacional, que engloba trabalhos tanto da Sociolinguística Interacional quanto da Análise da Conversa Etnometodológica. Apresentamos, portanto, os principais conceitos mobilizados na análise dos dados aqui expostos.

\section{$2.1 \mathrm{O}$ protagonismo na mediação}

De acordo com autores da área do direito que se dedicam ao estudo da mediação, mais precisamente Spenger (2010, p. 97), a atividade profissional da mediação, de forma geral, "permite o desenvolvimento do protagonismo, ou seja, fortalece a capacidade de as pessoas analisarem situações e tomarem decisões efetivas sobre si mesmas”. A entrevista de mediação, por sua vez, conforme compreendida por Vasconcelos (2006), é um espaço comunicativo

\footnotetext{
${ }^{2}$ T1, T2 e T3 são abreviações utilizadas para exemplificarmos a organização sequencial dos Turnos de Fala. Logo, T1 corresponde a um primeiro turno de fala e assim sucessivamente.
} 
que contribui para que os futuros mediandos desempenhem com mais autonomia seu papel de protagonistas na resolução do conflito.

$\mathrm{Na}$ verdade, essas posições se coadunam com a visão de Greatbatch e Dingwall (1994), segundo a qual é em turnos de fala que devemos localizar nossos insumos para podermos estudar o comportamento comunicativo de todos os participantes da mediação. Se é verdade que "dizer é fazer" (AUSTIN, 1962), ou seja, que a linguagem, muito mais do que representar o mundo em que vivemos, é o próprio meio pelo qual construímos, preservamos e modificamos o nosso mundo, humano e não humano, dotando-a de um caráter intrinsecamente performativo -, os turnos de fala são o espaço conceitual em que o sujeito exerce o protagonismo na linguagem. A análise do protagonismo na linguagem deve ser feita, portanto, com atenção especial ao ambiente sequencial em que a linguagem é usada e ao fato de que um turno de fala corrente revela, em sua forma, como a ação é composta (o que o participante entendeu, o que foi dito anteriormente), projetando expectativas em relação ao que deverá ser dito no turno seguinte, como ação relevante em resposta. Em outras palavras, cada turno de fala é duplamente contextualizado pelo que veio antes e pela projeção de expectativas de ação relevante para o que virá depois. As ações realizadas em um turno de fala tornam-se, assim, o foco de análise do protagonismo neste artigo, em consonância com a posição defendida por Schegloff (1995).

Especificamente em relação ao tema "protagonismo", endossamos o argumento de Enfield (2013) acerca de ação e agência, no âmbito da Análise da Conversa. O autor define ação como "comportamento controlado que é exercido como meio para se atingir uma meta, e que pode ser interpretado como possuindo uma finalidade" (ENFIELD, 2013, p. 83), como pegar um copo de água porque está com sede, abrir a porta para sair etc. $\mathrm{Na}$ esteira do pensamento fenomenológico, a ação é racional, porque detém objetivos conhecidos.

É nesse momento que o papel do intérprete da linguagem - e seu protagonismo - torna-se fundamental: é por meio de seu comportamento responsivo que se pode dotar de significado a ação contida na elocução de um falante, respondendo à pergunta "por que isso agora?". Para ele, a agência, no comportamento orientado por finalidades, consiste em: i) flexibilidade, que diz respeito à capacidade de controlar o comportamento, compô-lo (via seleção, funcionalização e execução) e subentendê-lo (i.e., antecipá-lo para o intérprete); e ii) Relatabilidade, ou seja, ser avaliado e 
autorizado pelo outro, e também dispor de obrigações de natureza moral. É dessa forma que entendemos o protagonismo na linguagem, em uma perspectiva microinteracional.

\subsection{As fases de um evento comunicativo}

Neste trabalho, considerando os aspectos discursivos da entrevista, esta é compreendida como uma prática social de linguagem com formas relativamente estáveis em sua realização. Essa assertiva dialoga com os apontamentos de Ten Have (1999), no âmbito da Análise da Conversa, a respeito dos formatos mais ou menos genéricos das interações, os quais são construídos no acontecer interacional. De acordo com Ten Have, esses formatos são estruturas sequenciais da atividade de fala.

O autor vai, por meio de suas colocações, ao encontro de Drew e Heritage (1992) e da discussão estabelecida por eles quanto à "organização estrutural global"' das interações. Tal estrutura é um dos fatores que marcam a distinção entre as interações cotidianas e as interações institucionais. De acordo com os autores, as interações institucionais apresentam formatos específicos - ou fases - construídos com base em sequências fundamentais, que permitem a percepção de como os participantes se orientam em razão das ações de seu interlocutor, ou seja, apresentam o caráter de monitoramento e de coconstrução das ações.

Embora não sejam estanques e rígidas, as fases são elementos importantes para a compreensão de um dado encontro comunicativo, visto que sinalizam os tipos de ações dos participantes. Nesse sentido, um estudo sistemático sobre as fases de uma atividade de fala institucional, tal como a mediação, pode auxiliar os profissionais envolvidos nessa tarefa a compreenderem, orientarem e monitorarem tanto as suas ações como as dos participantes, para que possam alcançar os objetivos da atividade de forma mais satisfatória, com base no que é tornado relevante pelos envolvidos na questão.

Em estudos interacionais sobre a organização da interação institucional, encontramos discussões importantes a respeito das entrevistas clínicas. Clark e Mishler (2001), em trabalho que descreve interações médicopaciente, analisam como residentes gerenciam e interferem nas narrativas de

3 "the overall structural organization". 
seus pacientes e como essas interferências mediante determinadas estruturas discursivas podem facilitar, ou não, a atividade de consulta médica.

Os autores afirmam, de forma crítica, que a entrevista, pautada em um modelo clínico tradicional, apresenta estrutura rígida, sendo constituída, predominantemente, por perguntas cuja resposta pode ser sim ou não. Clark e Mishler transparecem, com isso, que essa rigidez na estrutura do evento está atrelada à necessidade de manutenção da "voz da medicina", visto que as perguntas realizadas pelos médicos tendem a restringir as respostas dos pacientes, limitando-os ao papel de respondentes. As ações corretivas, aquelas que demandam repetições e reformulações por parte dos clínicos, são ações despreferidas nesse tipo de entrevista.

Esse modelo de entrevista clínica foi bastante discutido por Mishler (1984, 1986, 1992), que trouxe à tona o caráter de coconstrução das narrativas, ressignificando o papel do médico nesse tipo de atividade. $\mathrm{O}$ autor enfatiza, em seus estudos, a necessidade da escuta ativa como recurso para a construção do diagnóstico clínico. Argumenta, ainda, que o discurso que constitui a atividade "entrevista clínica" é contextual e construído tanto pelo médico como pelo paciente.

Diante disso, no que se refere à organização do encontro e ao papel do médico nessa interação, Mishler $(1992,1995)$ afirma que as entrevistas médicas se estruturam em algumas ações médicas, a saber: pedidos de confirmação, explicação e informação. Tais ações são dispostas em fases do encontro e organizadas em pares adjacentes de pergunta e resposta. A tese de Mishler é, portanto, que as estruturas discursivas podem favorecer ou dificultar a narrativa dos participantes e, consequentemente, a elaboração de diagnósticos eficazes e ancorados nas necessidades dos pacientes.

Nesse sentido, os autores enfatizam a necessidade de dar atenção à fase da consulta médica voltada para a narrativa do paciente. Eles afirmam que a história do paciente é realizada em um contexto específico de pedidos e detalhamentos e, portanto, deve ser reconhecida como esforço construído em conjunto para dar sentido a um problema dentro de um contexto de acontecimentos.

As colocações dos autores vão ao encontro da perspectiva adotada neste trabalho no que se refere às fases da entrevista de mediação. Em defesa de um tipo de mediação mais humanista, em que se valoriza o que o outro tem a dizer sobre suas questões, entende-se que o tipo de atividade em estudo deve ser construído considerando os objetivos institucionais da atividade e, sobretudo, acolhendo as demandas dos participantes da interação. 
Ainda nesse sentido, considerando que na Vara da Família relações parentais e bem-estar de incapazes estão comumente em questão, faz-se indispensável que a mudança nas relações conflituosas se efetive, visto que a continuidade na convivência entre os envolvidos e as emoções, sentimentos e elos afetivos que compõem o sujeito no mundo são pontos que estão em jogo quando um mediador se depara com os participantes da atividade de mediação nesse contexto.

\subsection{Sociolinguística interacional}

Por ser um trabalho baseado em dados reais de fala-em-interação e por acreditarmos que a linguagem tem papel ativo na criação do mundo social, ancoramo-nos nos pressupostos teóricos da Sociolinguística Interacional como uma das ferramentas de análise dos dados aqui apresentados. Dessa forma, faz-se necessário apresentar a contribuição dessas vertentes teóricas para o uso da linguagem.

A partir dos postulados de Goffman (2002 [1979]), entendemos que os encontros sociais, comuns à vida humana, são organizados de forma que os participantes possam assumir diferentes posições em relação àquilo que se faz e se diz, ao longo de um mesmo encontro, em diferentes momentos.

Diante dessa premissa, o autor estabeleceu o conceito de estrutura de participação, uma vez que, para ele, o modelo diádico de comunicação apresentava falhas e mostrava-se ineficiente diante das diferentes posições assumidas pelo participante dentro da situação de comunicação. Assim, o autor repensou a noção de falante e de ouvinte e, portanto, estabeleceu categorias que ampliassem essas noções.

Diante da perspectiva do falante, Goffman postulou os termos animador, autor e responsável. De maneira simplificada, podemos dizer que o animador é aquele que produz a fala; o autor é o dono, aquele que cria o script da fala; e o responsável é aquele que pode ser responsabilizado pela posição assumida na fala. É comum as três noções recaírem sobre a mesma pessoa, mas não necessariamente. ${ }^{4}$

Já para a posição de ouvinte, o autor considerou a condição de participante ratificado ou não no encontro social. Os participantes ratificados são os endereçados, ou seja, aqueles que têm a "atenção visual"

\footnotetext{
${ }^{4}$ Para uma descrição mais detalhada de cada um desses "tipos de falante", ver Goffman (2002 [1979], p. 133-138).
} 
do falante e, ainda, têm a possibilidade de assumir o papel de falante, em outro momento da interação.

A partir do exposto e diante da dinamicidade dos papéis assumidos na interação, o autor estabelece as noções de alinhamento, footing e enquadre. Segundo Goffman (2002 [1979]), os footings podem ser introduzidos, sustentados ou modificados no decorrer de determinado encontro social. Nesse sentido, pode-se dizer, de acordo com o autor, que o footing é uma mudança do alinhamento, da postura, da projeção do "eu" de um participante na sua relação com o outro, consigo próprio e com o discurso a ser construído. A natureza do footing, assim como a do enquadre, é dinâmica. Assim, muitas vezes os participantes precisam reconstruir o seu entendimento sobre a situação.

As modificações de footing podem ser sinalizadas, por exemplo, via alternância de código, de registro, mudança de tom, de postura corporal, ou seja, por meio de diferentes pistas de contextualização. Essas mudanças podem ocorrer por aspectos pessoais ou de estilo (uma fala afável ou rígida), papéis sociais (a fala da mediadora, a fala de mãe etc.) e papéis discursivos (por exemplo, o papel de entrevistador, respondedor etc.). Essas características do footing colaboram para o estabelecimento do enquadre da situação. Dessa forma, pode-se entender que o enquadre determina a maneira como sinalizamos para a interpretação que será feita pelo outro e, ao mesmo tempo, como nos atentamos para o modo que processamos os sinais que exteriorizam os enquadres dos outros participantes.

Ainda com base na noção de enquadre, outro conceito importante, trazido pela Sociolinguística Interacional, é o de esquema de conhecimento (TANNEN; WALLAT, 2002). Para as autoras, esse conceito é um tipo de estrutura de expectativa que se refere ao entendimento do discurso por preencher informações não proferidas, decorrentes do conhecimento adquirido em interações anteriores. Essas experiências determinam expectativas acerca de pessoas, objetos, eventos e cenários no mundo, determinando também expectativas acerca de um encontro de serviço específico. Por meio de nossos esquemas de conhecimentos, podemos, portanto, identificar determinada situação e dar sentido ao que é dito.

Diante do exposto, podemos afirmar que as expectativas sociais possibilitam a interpretação de um evento comunicativo, que é criada e recriada pelos participantes no contexto de produção da linguagem. É dessa forma que os participantes identificam qual ação está sendo desempenhada 
na interação. Tal constatação ratifica a relevância de um estudo sobre as fases de um tipo de atividade profissional.

\subsection{As narrativas}

A partir de um viés estrutural, uma vez que compreende a narrativa a partir de elementos organizadores, Labov (1972) a define como o método de recapitular as experiências passadas por meio da combinação de uma sequência verbal de orações com uma sequência de eventos que verdadeiramente ocorreram.

Por meio das narrativas, conseguidas a partir de entrevistas, Labov (1972) observou a recorrência de determinados elementos que constituíam a sua estrutura global. Segundo o autor, as orações narrativas se organizam em uma estrutura regular dividida em seis partes: resumo, orientação, ação complicadora, avaliação, resolução e coda.

No âmbito da Psicologia Social, com ênfase na Sociolinguística Discursiva, Mishler (2002) discute a noção de temporalidade na narrativa, fazendo uma varredura desses conceitos a partir das diferentes perspectivas teóricas. Segundo o autor, a narrativa é mais do que uma sequência de ações coordenadas, ou, em suas palavras, "mais do que uma coisa depois da outra” (MISHLER, 2002, p.98). Para o autor, é necessário que haja alguma conexão significativa entre os fatos narrados para que os ouvintes/leitores compreendam o todo de um dado discurso e percebam o seu propósito.

$\mathrm{Na}$ fundamentação de sua crítica à ênfase dada ao tempo cronológico das narrativas, Mishler (2002) afirma que, como indivíduos, somos passíveis a mudanças e desenvolvimento. Tal assertiva implica o modo como retratamos nossas experiências. Segundo o autor, "re-historiamos" o nosso passado de acordo com a pessoa que nos tornamos, havendo, portanto, diferenças significativas entre o evento narrado e a maneira como reportamos esse evento em momentos distintos de nossa vida.

Outro ponto muito importante do trabalho do autor é a compreensão de que mais do que analisar a estrutura da narrativa, é fundamental observar como um narrador seleciona e dispõe suas experiências a fim de que elas demonstrem o ponto que se pretende narrar, bem como é central, em estudos de construção de identidade em narrativas, perceber as estratégias utilizadas por um narrador para contar sua história de dada maneira em detrimento de tantas outras. Tais características favorecem o entendimento do protagonismo dos participantes na entrevista de mediação. 


\subsection{Formulação e reformulação}

Como precursores da definição de formulação, Garfinkel e Sacks (1970) percebem que uma tarefa legítima dos falantes é o preenchimento das lacunas deixadas na conversa, devido às expressões indexicais (ou indiciais). Ao preencher esses gaps, é fundamental que o contexto seja fornecido, a fim de que o entendimento efetivo entre os falantes ocorra. A partir desse fenômeno interacional, Garfinkel e Sacks (1970) estabelecem, então, que as formulações são práticas restauradoras, pois buscam esclarecer a lacuna de sentido deixada por uma expressão indexical.

Em um texto considerado basilar na área, como primeira definição de formulação, os autores afirmam que "é possível encontrar participantes da conversa no decorrer de uma conversa, e como característica reconhecida dessa conversa, formulando sua conversa" (GARFINKEL; SACKS, 1970, p. 170). Tal definição retoma a propriedade da relatabilidade, ${ }^{5}$ visto que demonstra a capacidade dos membros em definir o que estão fazendo na conversa. Ainda quanto à característica relatável da fala, os autores ressaltam que "um membro pode tratar um ou outro trecho da conversa como oportunidade para descrever aquela conversa, explicá-la, ou caracterizá-la, ou explaná-la, ou traduzi-la, ou resumi-la” (GARFINKEL; SACKS, 1970, p. 170).

A partir dessas definições, os autores assumem que a formulação é uma prática que, além de feita mediante conversa, é também reconhecida pelos participantes como parte desta. Sendo assim, formular é ainda um colóquio autoexplicativo, visto que é "dizer-em-tantas-palavras-o-queestamos-fazendo" (GARFINKEL; SACKS, 1970, p. 171).

É possível afirmar, com base nas definições trazidas, que a formulação é a demonstração do entendimento sobre o que foi dito anteriormente na conversa. Diante disso, Garfinkel e Sacks (1970) salientam que todo falante, em algum momento da interação, faz uso da formulação como expressão de subjetividade, isto é, salienta para o interactante quais são as suas impressões, sensações e emoções diante do que acaba de ser dito.

Heritage e Watson $(1979,1980)$, também, já em Análise da Conversa Etnometodológica, aprofundaram o conceito de formulação. Os autores

\footnotetext{
${ }^{5}$ Resumidamente, relatabilidade é um princípio etnometodológico segundo o qual os atores sociais visibilizam suas ações uns para os outros, atribuindo a elas compreensão e significado (GARFINKEL, 1967).
} 
definem formulação, de forma genérica, como prática utilizada pelos participantes para demonstrarem uns para os outros o entendimento do que foi dito ou feito em um ponto da conversa (HERITAGE; WATSON, 1979). Afirmam ainda que a formulação pode ser dividida em duas subclasses: a produzida por quem detém o conhecimento e está informando algo (newsdeliverer), ou por quem recebe um novo conhecimento (newsrecipient). O segundo tipo é o foco do trabalho dos autores, uma vez que o interesse de Heritage e Watson $(1979,1980)$ recai sobre as formulações, nas quais os estados de sentimento já foram descritos e negociados anteriormente.

Como características fundamentais da prática de formulação, os pesquisadores também ressaltam sua relação com as expressões indiciais, ou seja, a sua capacidade de definibilidade de sentido, bem como afirmam que as formulações são organizadas sequencialmente, visto que são realizadas essencialmente em resposta a uma ação anterior. Dessa maneira, os autores estipulam que as formulações são organizadas em pares adjacentes. $\mathrm{Na}$ primeira parte do par (PPP) ocorre a formulação e, na segunda parte do par (SPP), a decisão. A decisão tem dupla possibilidade de ocorrência confirmação e desconfirmação.

Heritage e Watson (1979) relatam, também, a imensa utilidade prática das formulações. Por meio dessa qualidade, é possível entender que formular é uma prática pervasiva, pois diversas ações podem ser implementadas por meio dela, e pode ocorrer em qualquer contexto da vida humana.

Embora sejam práticas universais, elas apresentam propriedades centrais e específicas, tais como a preservação, o apagamento e a transformação, que se relacionam à demonstração de entendimento e podem ocorrer concomitantemente. Tais propriedades abrem margem para a discussão acerca da neutralidade da prática de formular. De acordo com Hutchby (2005), as escolhas realizadas pelos falantes para retomar e reenquadrar a fala do outro não são de forma alguma aleatórias e ingênuas. Desse modo, para o autor, formular não é uma prática neutra.

Além de apresentarem as propriedades centrais da formulação, Heritage e Watson $(1979,1980)$ introduzem dois tipos de formulações conversacionais produzidas por quem recebe a informação: formulação do cerne da fala (gist) e formulação de resultado (upshot). Os autores afirmam que esses tipos de formulações demonstram o entendimento sobre a fala que foi produzida até o momento na conversa. Heritage e Watson (1979, 1980) descrevem com mais atenção as formulações de gist, uma vez que elas retomam a fonte do problema, bem como é o lugar das leituras candidatas, 
ou seja, o momento da conversa em que os participantes demonstram a sua compreensão a respeito do que foi falado.

Em contraposição à definição de Garfinkel e Sacks (1970), Bilmes (2011) afirma que formulação é, na verdade, uma reformulação, uma vez que a conversa anterior já é constituída por formulações. A afirmação de Bilmes está interligada à discussão sobre a semântica ocasionada, que é o estudo de estruturas de expressões significativas em ocasiões reais de conversa.

$\mathrm{O}$ autor associa o estudo de formulação a aspectos significativos da conversa, como a generalização e especificação. Para ele, as formulações são niveladas de acordo com seu nível de generalidade. Tal fenômeno é exemplificado pelo autor com a noção de categorização da palavra árvore. Segundo Bilmes (2011), quando essa palavra é utilizada, cria-se um enquadre mais geral do que, por exemplo, pinheiro (tipo específico de árvore) e mais específico do que planta.

Um ponto bastante interessante quanto à compreensão do autor a respeito do tema é o fato de que a formulação pode ter um só referente, uma única significação. Segundo o autor, uma narrativa é passível de ser uma formulação, uma vez que ela pode ter um referente, mesmo que seja um evento ou um acontecimento passado, tal como um jogo. Sendo assim, nas palavras do autor, formulação é uma forma de "identificar, categorizar, descrever e persuadir, isto é, são aspectos retóricos e construtivos de realidade de ação linguística" (BILMES, 2011, p.133).

Portanto, a partir dos conceitos expostos nesta revisão teórica acerca das formulações, sobretudo a definição apresentada por Bilmes, trataremos, a princípio, a formulação como uma primeira versão e a reformulação como uma segunda versão.

\section{Contextualizando o caso}

Em um momento em que a mediação se encontrava em expansão no país, mais precisamente no ano de 2007, o primeiro autor, coordenador do grupo de pesquisa Interação em Contextos Institucionais (ICI), fez contato com uma assistente social (e bacharel em direito) que utilizava a mediação como estratégia para o estudo social de seus casos em uma Vara da Família no interior do estado do Rio de Janeiro. A partir desse contato com a profissional e da autorização da juíza da Vara da Família, pudemos acompanhar e gravar três casos desenvolvidos por meio do trabalho de mediação. 
O processo analisado neste artigo trata de um de Pedido de Guarda em que se contemplava a possibilidade de o pai deter legalmente a guarda do filho, Matheus, então com oito anos, e da filha, Ana Cristina ${ }^{6}$, com onze anos. Por meio do processo, o requerente solicitou um estudo social de caso, a fim de que houvesse espaço de fala para os menores expressarem seus desejos com a orientação de profissionais habilitados para essa finalidade. Em razão das especificidades do caso envolvendo o bem-estar físico e psicológico de duas crianças, o processo foi encaminhado pela juíza para o estudo social endoprocessual, a ser realizado por uma psicóloga e por uma assistente social. A psicóloga ficou responsável pelo contato com os menores, e a assistente social ficou incumbida de conhecer a versão dos pais, escolhendo a mediação para essa finalidade. Ao final do trabalho das profissionais, fez-se um relatório com os pontos de acordo alcançados, a ser ratificado em audiência.

Foram realizados, no total, cinco encontros: dois encontros constituíram as entrevistas de mediação, ou seja, foram realizados somente com a presença da mediadora e de um dos envolvidos, e três encontros ocorreram com a presença de Rui, o requerente, Arminda, a requerida, e Sônia, a mediadora, compondo as sessões de mediação.

\section{Metodologia}

Este estudo é afiliado a uma tradição de pesquisa qualitativa de base interpretativa (DENZIN; LINCOLN, 2000), em que o ponto de vista dos participantes norteia as análises aqui construídas. Compreende-se que a realidade é construída e ressignificada pelo ser humano e por suas ações, sendo, portanto, indispensável que se considere os processos e os significados que os participantes atribuem aos fatos.

É importante destacar que a noção de realidade (BERGER; LUCKMANN, 1978) é tomada aqui de forma mais abrangente, visto que os múltiplos usos da linguagem nos diversos contextos sociais fazem com que não haja uma realidade única, mas várias. Desse modo, admite-se que a linguagem não só possibilita a construção do mundo social, como também é condição para que ele exista, isto é, os significados não são resultados de

\footnotetext{
${ }^{6}$ Os nomes dos participantes foram trocados para garantir a privacidade e a integridade de todos os envolvidos.
} 
intenções individuais, mas sim de ações compartilhadas e construídas em conjunto.

Segundo Moita Lopes (1994) e Denzin e Lincoln (2000), para acessar os significados atribuídos pelos participantes, a escolha do instrumento de pesquisa é fator preponderante. Diários, gravação em áudio e vídeo, entrevistas e documentos são ferramentas que apresentam descrições e interpretações do contexto pesquisado, o que favorece a pesquisa qualitativa e interpretativa.

Quanto ao método de pesquisa escolhido, utiliza-se o estudo de caso, pelo qual se investiga ocorrências detalhadas de um fenômeno em um cenário específico - a entrevista de mediação, neste caso. Estudo de caso é, segundo Miles e Huberman (1994, p. 25), uma "unidade de análise, que pode ser um indivíduo, o papel desempenhado por um indivíduo ou uma organização, um pequeno grupo, uma comunidade ou até mesmo uma nação. Todos esses tipos de caso são unidades sociais".

Os nomes dos participantes do processo de mediação foram alterados de maneira que houvesse entre o nome original e o inventado uma semelhança fônica e silábica. Por exemplo, se houvesse nos dados alguém cujo nome fosse Mariana, seu nome seria trocado para Juliana. Os nomes das cidades, ruas e empresas particulares também foram trocados seguindo o mesmo critério de semelhança fônica e silábica.

Diante do exposto, é pretensão deste artigo fornecer bases teóricas para o desenvolvimento das conclusões e para a construção de uma teoria $a$ posteriori. Uma análise de dados feita empiricamente e voltada para detalhes únicos da interação humana torna-se, desse modo, uma forma contundente de fazer pesquisa qualitativa.

\section{Análise dos dados}

As interações apresentam formatos que podem ser deduzidos a partir das contribuições de seus participantes, que reconhecem as ações em curso e são capazes de relatar o que está acontecendo em momentos específicos da interação. Com isso, consequentemente, conseguem demarcar etapas/fases de uma atividade por meio de finalidades particulares, construídas por tipos de discursos específicos. Ou seja, as fases de um encontro são construções de natureza endógena, êmica.

Quando pensamos em um tipo de atividade profissional, tal como a mediação, essa característica ganha destaque, visto que a organização da 
atividade em fases e a compreensão sobre elas podem contribuir para o entendimento global da atividade, levando o profissional a repensar suas práticas em função do que acontece na interação, em vez de se pautar pelas ações prescritas em manuais jurídicos do tipo "como fazer".

Desse modo, após escutar os áudios e estudar as transcrições dos casos de mediação pertencentes ao corpus do grupo de pesquisa ICI, percebeuse que as fases da entrevista de mediação constituíam-se como recorrentes e bem marcadas nas interações analisadas, possibilitando o processo de categorização e definição. Em estudos desenvolvidos pelo grupo de pesquisa ICI são analisadas e discutidas cinco fases, categorizadas da seguinte forma: i) esclarecendo as regras do jogo; ii) conhecendo os participantes; iii) historiando o conflito; iv) entendendo o processo; e v) combinando a próxima etapa.

No que se refere especificamente à tarefa de categorização dos dados deste trabalho, é válido elucidar que a escolha dos verbos no gerúndio para a denominação das fases encontradas se deu pelo desejo de destacar o processo e a continuidade das ações. As fases não são tratadas aqui como estruturas rígidas e finalizadas; portanto, tratá-las no gerúndio, a nosso ver, permite essa ideia de continuidade e fluidez das ações.

Focaremos, aqui, na fase "historiando o conflito", 7 que acreditamos ser o momento em que os participantes da interação em análise têm a oportunidade de demonstrar, com sua narrativa, o protagonismo em suas histórias de vida, e, sobretudo, os rumos que querem dar a ela.

$\mathrm{Na}$ análise dos excertos dessa fase, discute-se que ela representa o cerne da interação, entre outros motivos, por ser o espaço onde os participantes podem desenvolver sua narrativa a respeito dos pontos de conflito. Oportunizar espaços e estimular os participantes a narrar suas dores, mágoas e sentimentos em um contexto de Vara da Família é, a nosso ver, uma estratégia discursiva/interacional que consolida a mediação como um espaço possível para o empoderamento do sujeito e, consequentemente, transformação das relações familiares.

$\mathrm{Na}$ fase em análise, a mediadora faz uso do discurso terapêutico, acolhendo as emoções dos participantes, por meio de avaliações encorajadoras ou de continuadores. A profissional estimula, com perguntas e pedidos de explicação, a narrativa dos participantes.

${ }^{7}$ Em artigos futuros serão estudadas as demais fases, ainda em processo de investigação. 
É importante ressaltar que a fase em estudo se caracteriza, ainda, por ser o momento em que a mediadora exerce a escuta ativa dos eventos narrados. Considerando que as emoções vêm à tona nessa fase da entrevista, Sônia se aproveita desse momento para obter a maior quantidade de informações a respeito de brigas entre o ex-casal e, com isso, perceber o nível da relação entre eles, compreendendo em que medida é possível estabelecer acordos.

Além disso, a ausência do outro na interação implica a necessidade da checagem de informações, já que, considerando os sentimentos e os interesses envolvidos, é natural que as perspectivas sobre um mesmo acontecimento sejam diferentes, havendo uma disputa para provar um dado ponto de vista, além da construção de identidades contrastantes. Nesse sentido, essa fase nos mostra como os participantes se posicionam diante dos conflitos, como se apresentam quanto às suas tarefas de mãe e pai, e como formulam suas dores e suas necessidades de mudança, ratificando o espaço profissional da mediação como restaurador da agentividade do sujeito no que tange à tomada de decisões sobre sua própria vida.

Para exemplificarmos a fase "historiando o conflito", apresentamos um excerto extraído da entrevista realizada com Rui. O imóvel em que o excasal vivia e o fato de o pai tomar, sozinho, conta dos filhos são os assuntos predominantes:

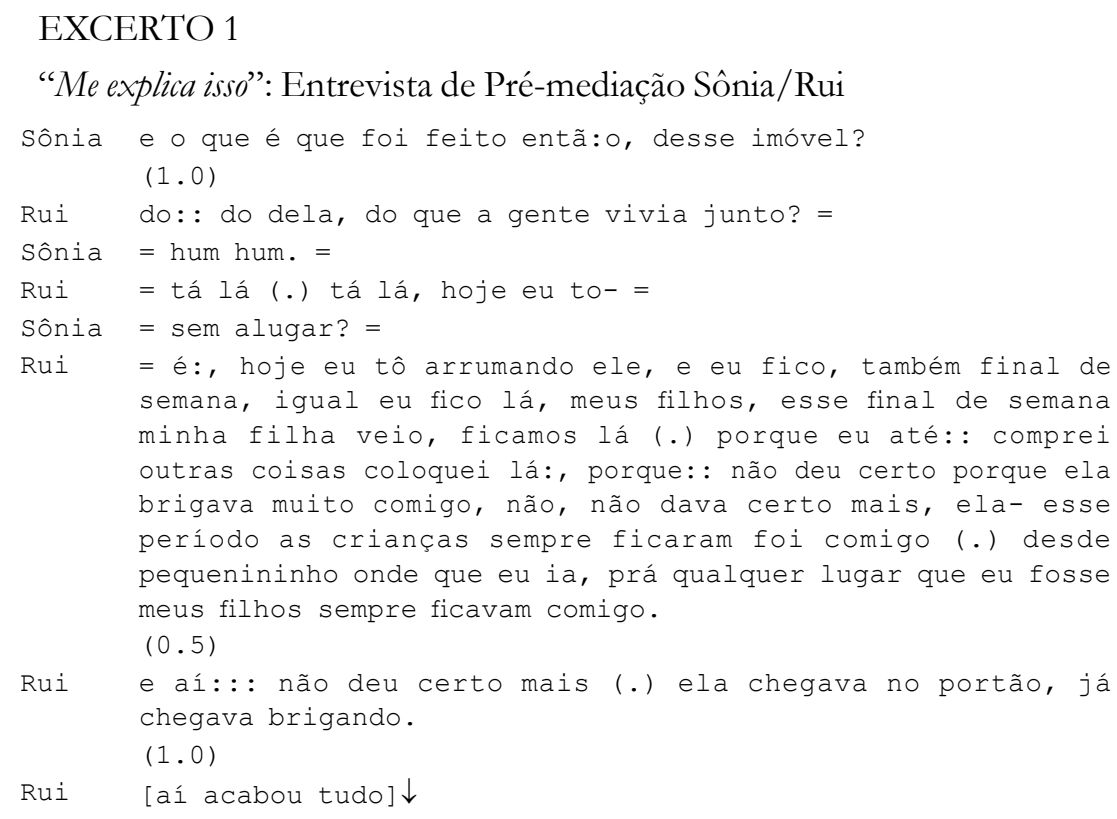




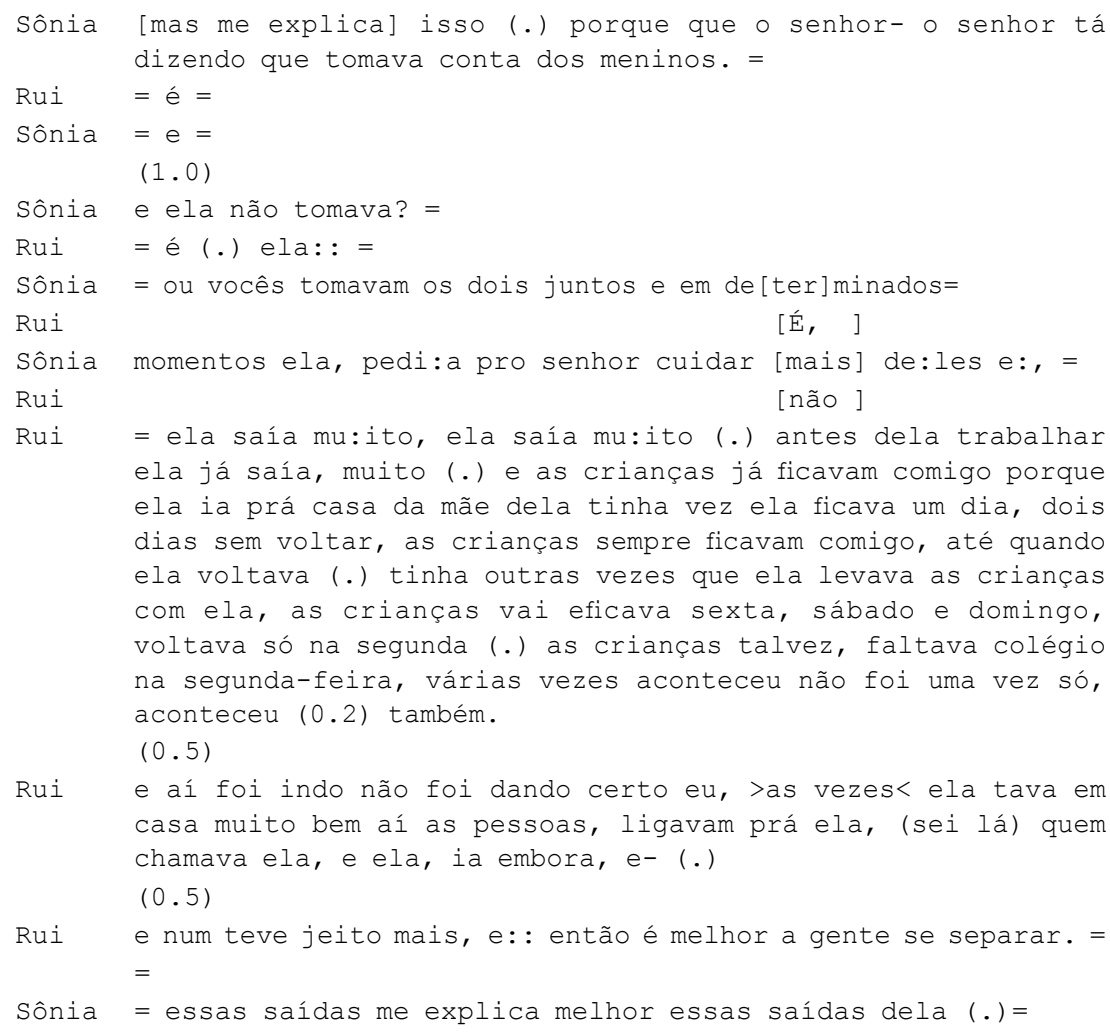

Antes da realização da pergunta que entendemos dar início à fase "historiando o conflito" ("e o que é que foi feito entã:o, desse imóvel?"), a mediadora vinha realizando a construção do perfil de Rui, bem como buscava compreender questões pontuais acerca do tempo de relacionamento e da proximidade emocional e geográfica entre o requerente e a requerida. O imóvel no qual o ex-casal morava é um dos pontos de divergência entre os participantes. Esse tema foi bastante problematizado na entrevista com Arminda, bem como retomado nas sessões de mediação. Diante disso, quando tem a oportunidade de abordar essa questão, Sônia destaca a problemática do imóvel, a fim de dar a Rui a oportunidade de contar a sua versão. Percebe-se, pela forma como Sônia formula seu questionamento, sua tentativa em compreender esse tema que é um ponto de conflito. A expressão conclusiva "entã: o" e o demonstrativo "desse" confirmam que Sônia está retomando o assunto. 
No entanto, essa retomada não fica clara para Rui e, após o pedido de explicação da mediadora e da pequena pausa na linha 3, o mediando realiza uma checagem de entendimento, procurando especificar a qual imóvel a mediadora se referia ("do: : do dela, do que a gente vivia junto?"). Notamos que Rui inicia a sua resposta reconhecendo ser a requerida a proprietária do imóvel, mas, em seguida, reformula sua própria fala modificando a ideia de posse do imóvel, pelo caráter de vida compartilhada na residência.

Após o continuador "hum hum." de Sônia na linha 4, o requerente, em sua resposta, não apresenta informações precisas a respeito do imóvel e tenta iniciar uma narrativa “tá lá (.) tá lá, hoje eu to-". Diante da resposta evasiva de Rui, na linha 5, a pergunta de Sônia é bem específica a respeito da situação do imóvel: “sem a lugar?”. Em seu turno responsivo, o requerente confirma que a casa não está alugada e retoma a narrativa, iniciada em seu turno anterior: "é: , hoje eu tô arrumando ele," (linha 7).

Entre as linhas 1 e 7 há um movimento que merece destaque no que se refere ao término de uma fase e início da outra. A fase "conhecendo os participantes" estava em curso quando surge na conversa algo que, para a mediadora, deve ser narrável pelo outro. Sônia monitora o que vem sendo construído por Rui e evidencia o que considera relevante para o entendimento do conflito. Vejamos um trecho da sequência imediatamente anterior à que inicia a fase em estudo:

EXCERTO 2

Entrevista Sônia/Rui: fase "conhecendo os participantes"

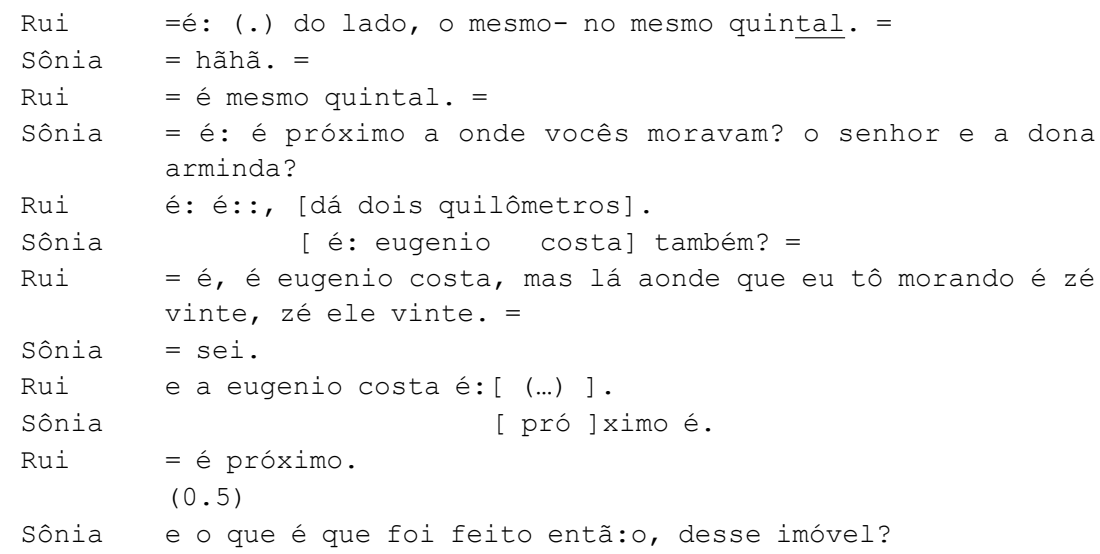


Os participantes construíam o entendimento sobre a proximidade entre as casas de Rui e Arminda, com sucessivas perguntas da mediadora que nos parecem querer construir um quadro da situação em estudo por ela. A mediadora, por meio de suas perguntas, pede referências para a construção desse quadro. Em certo momento da interação, quando as referências de localização parecem ser satisfatoriamente construídas, ela modifica o estilo de sua pergunta, ou melhor, o enquadre que, até então, era o de checagem de entendimento ("é: é próximo a onde vocês moravam? o senhor e a dona arminda?") e passa a ser o de pedido de explicação ("e o que é que foi feito entã:o, desse imóvel?"), o que favorece a narrativa do mediando, visto que, enquanto as perguntas de checagem de entendimento pedem respostas do tipo sim ou não, as de pedido de explicação pedem formulações mais complexas. Essa mudança de enquadre é analisada aqui como uma pista de contextualização (GUMPERZ, [1982] 2002) para tratarmos das mudanças de fase na atividade profissional entrevista de prémediação.

É nesse momento em que o enquadre muda que percebemos, também, que as relações de assimetria no turno de fala se alteram. A entrevista de mediação é uma atividade de fala institucional e, como tal, à representante da instituição é conferida a autoridade de decidir como a interação deve ser conduzida. E, a partir desse ponto da interação, Rui passa a ter maior espaço de fala para narrar seu ponto de vista acerca das questões conflituosas que o levaram à Justiça.

O turno narrativo que sucede a pergunta de Sônia, na linha 6, funciona, portanto, como a explicação de Rui quanto à situação do imóvel. Faz-se necessário informar, para melhor compreensão a respeito do conflito envolvendo o imóvel, que ele foi alvo de um incêndio quando Arminda e os filhos nele moravam. A requerida sugere, em sua entrevista de mediação, que Rui tenha algum tipo de responsabilidade por esse incêndio.

Rui, entre as linhas 7 e 9, evocando a sua identidade de homem habilidoso, pai afetivo e presente, afirma que não alugou a residência pois a está reformando e adquirindo novos objetos para a casa, além de ser um local onde pode ficar com seus filhos. Percebe-se que a primeira parte da narrativa do mediando é composta, portanto, por um item lexical confirmativo ("é:",) que responde diretamente à pergunta de Sônia, na linha 6 , além de conter a sua justificativa para o fato de não ter alugado a casa. 
A justificativa de Rui é realizada, inicialmente, por três unidades de construção de turno (doravante $\mathrm{UCT}^{8}$ ) clausais, com verbos no presente, reforçando, com isso, o constante uso do espaço: "hoje eu tô arrumando ele, e eu fico, também final de semana, igual eu fico lá". O fato de Rui ter escolhido o argumento do reparo do imóvel para iniciar a sua justificativa demonstra a orientação do mediando quanto aos aspectos da lei. Sabemos que, em uma união estável, como no caso de Rui e Arminda, é levado em conta nas deliberações de divisão de bens e herança o que cada um investiu em determinado bem quando daquela união. Rui parece estar orientado para essas especificidades da lei, visto que destacou, na linha 3 , a vida que levavam juntos na referida casa ("do que a gente vivia junto?") e, nas linhas 7 e 9, o investimento que vem realizando ("hoje eu tô arrumando ele"; "comprei outras coisas coloquei lá").

A partir da linha 8 , Rui dá início às suas sequências de narrativas. Observa-se inicialmente a estrutura mínima de uma narrativa, com duas elocuções no passado costuradas por uma juntura temporal (LABOV, 1972). Para exemplificar o uso do imóvel, o mediando conta sobre seu fim de semana com a filha: "esse final de semana minha filha veio, ficamos lá”. É, portanto, possível recapitular um evento no passado e compreender o porquê de essa experiência estar sendo narrada, diferentemente, por exemplo, das duas UCT sentenciais na linha 9 "“comprei outras coisas coloquei lá:"). Compreendemos o motivo de ele fazer menção às compras, mas essas ações não são entendidas como um evento narrativo por não apresentar elementos suficientes que retomem um momento e um acontecimento específico no passado.

A fase "historiando o conflito" é, a nosso ver, o momento da interação em que observamos uma mudança quanto à manutenção do piso conversacional. Nesta fase, a mediadora permite que o mediando formule suas questões, conte de forma mais livre os motivos que levaram os participantes a recorrer à Justiça e, dessa forma, não interrompe o turno de Rui, mas também não realiza, nesse excerto, nenhum tipo de alinhamento ao que está sendo contado.

\footnotetext{
${ }^{8}$ Em Análise da Conversa, as elocuções da fala são definidas como UCT e podem ser de quatro tipos, de acordo com sua extensão: lexical (uma só palavra), sintagmática, clausal (um núcleo verbal) ou sentencial (mais de um núcleo verbal) (ver SACKS; SCHEGLOFF; JEFERSON, 2003).
} 
Nesse sentido, na linha 10, o entrevistado inicia uma nova história, que não mais se relaciona ao imóvel. Rui conta à mediadora o que para ele seria o motivo do fim de seu relacionamento com Arminda. Há, nesse momento da interação, um movimento bastante interessante. $\mathrm{Na}$ ausência da outra parte, o mediando constrói a sua versão, responsabilizando a parte ausente pelo fim do relacionamento. Além disso, Rui se apresenta na narrativa como um homem paciente por ter suportado as brigas de sua ex-companheira e, sobretudo, como um pai responsável e presente, ao passo que, segundo ele, Arminda não era uma mãe tão comprometida, pois delegava a ele os cuidados dos filhos: "não deu certo porque ela brigava muito comigo, não, não dava certo mais, ela- esse período as crianças sempre ficaram foi comigo (.) desde pequenininho onde que eu ia, prá qualquer lugar que eu fosse meus filhos sempre ficavam comigo." (linhas 10 a 13).

Após esse turno, na linha 14, há uma pausa de cinco segundos. Como a mediadora não toma o turno, o mediando apresenta o desfecho de sua segunda sequência narrativa "e aí:: : não deu certo mais (.) ela chegava no portão, já chegava brigando." (linhas 15 e 16), reforçando a personalidade agressiva da requerida. Há mais uma pausa na linha 17 e, em seguida, uma breve sobreposição das falas do mediando e da mediadora. Rui repetia o desfecho de sua narrativa quando a mediadora faz a sua intervenção diante do que foi narrado.

Na linha 19, Sônia, após escutar tudo o que foi dito por Rui, seleciona como relevante o cuidado com os meninos. Após a formulação de um pedido de explicação (“[mas me explica] isso"), iniciada por uma conjunção adversativa, a mediadora faz uma pergunta marcando a diferença entre o discurso de Rui e o evento em si. Ela, por meio de sua pergunta, demonstra entender que a narrativa de Rui é uma versão, parcial e intencionada, dos acontecimentos que envolvem o casal e seus filhos: "porque que o senhor- o senhor tá dizendo que tomava conta dos meninos." (linhas 19 e 20). Com isso, entendemos que a mediadora não se alinha à versão narrada por Rui - em busca da garantia da igualdade de direito entre as partes e em função do compromisso com a veracidade dos fatos, ela formula sua questão destinada a Rui solicitando a ele mais elementos a respeito da acusação feita a Arminda, reformulada na linha 24: "e ela não tomava?”. Além disso, ao continuar a formulação de sua pergunta nas linhas subsequentes, a mediadora, ao passo em que pede explicação, assume a voz 
da instituição Vara da Família, com base em uma ideia contemporânea do dever com os filhos, para explicar a Rui que aquela instituição entende que é tarefa dele também tomar conta das crianças: "ou vocês tomavam os dois juntos e em de[ter]minados momentos ela" (linha 26) e "pedi:a pro senhor cuidar [mais] de:les e:" (linha 28).

Sônia, na estrutura de participação da entrevista de pré-mediação, em que eventos envolvendo outras pessoas são narrados, evoca a sua identidade profissional de terceira parte, "neutra e imparcial" (diante do conflito), ${ }^{9}$ para animar os interesses de Arminda, protegendo, de certa forma, a face positiva da requerida. Além disso, percebemos a legitimação do discurso sobre a divisão de tarefas e responsabilidades com os filhos. Para a completude de seu turno de fala, mais uma vez, Sônia precisou se impor como representante da instituição, mantendo a sua fala, mesmo com as tentativas de tomada de turno de Rui (linhas 27 e 29).

Após a análise do excerto representante da fase "historiando o conflito”, realizado entre Sônia e Rui, apresentamos uma proposta de quadro, a ser usada em outras pesquisas. Contabilizamos em nosso esforço de análise quantitativa das fases 36 sequências conversacionais na fase "historiando o conflito". A seguir, vejamos esse panorama exposto no quadro 1.

\footnotetext{
9 Assume-se, neste trabalho, em consonância com Becker (1995), que "é impossível o juiz (ou o mediador) ser neutro, basicamente porque nem a ciência, nem o direito, nem o processo civil estão isentos de ideologia". Contudo, compreendemos que o mediador busca uma reflexão ética a respeito do conflito em análise. Nesse sentido, quando falamos de neutralidade e imparcialidade, falamos de um distanciamento do mediador considerando as versões e as complexidades que são levadas à tarefa de mediação.
} 
QUADRO 1 - Historiando o conflito quantitativamente

\begin{tabular}{|c|c|c|c|c|}
\hline Tópico tratado na fase & $\begin{array}{l}\text { Historiando } \\
\text { o conflito }\end{array}$ & $\begin{array}{c}\text { Tópico } \\
\text { iniciado } \\
\text { por Sônia }\end{array}$ & $\begin{array}{l}\text { Tópico } \\
\text { iniciado } \\
\text { por Rui }\end{array}$ & $\begin{array}{l}\text { Tópico } \\
\text { iniciado por } \\
\text { Arminda }\end{array}$ \\
\hline $\begin{array}{l}\text { A casa em que Rui e Arminda } \\
\text { residiam e os direitos sobre o } \\
\text { imóvel }\end{array}$ & Uma (1) sequência & $\mathrm{X}$ & & \\
\hline $\begin{array}{l}\text { A relação dos filhos de Rui e } \\
\text { Arminda com a nova companheira } \\
\text { de Sr. Rui }\end{array}$ & Uma (1) sequência & & & $\mathrm{X}$ \\
\hline O cuidado dos pais com os filhos & Uma (1) sequência & $\mathrm{X}$ & & \\
\hline O processo de pedido de guarda & Uma (1) sequência & & & $\mathrm{X}$ \\
\hline A pensão alimentícia & Duas (2) sequências & $\mathrm{X}$ & & \\
\hline $\begin{array}{l}\text { O novo relacionamento de } \\
\text { Arminda }\end{array}$ & Três (3) sequências & $\mathrm{X}$ & $\mathrm{X}$ & \\
\hline As visitas dos pais aos filhos & Duas (2) sequências & $\mathrm{X}$ & $\mathrm{X}$ & \\
\hline $\begin{array}{l}\text { A distância entre as casas do pai } \\
\text { e da mãe e as visitas aos filhos }\end{array}$ & Duas (2) sequências & $\mathrm{X}$ & $\mathrm{X}$ & \\
\hline $\begin{array}{l}\text { O comportamento da filha diante } \\
\text { das ameaças feitas contra seu pai }\end{array}$ & Uma (1) sequência & & $\mathrm{X}$ & \\
\hline A relação de Arminda e sua mãe & Uma (1) sequência & $\mathrm{X}$ & & \\
\hline O trabalho de Arminda & Uma (1) sequência & $\mathrm{X}$ & & \\
\hline $\begin{array}{l}\text { A presença de Maria Eduarda no } \\
\text { forró }\end{array}$ & Uma (1) sequência & & $\mathrm{X}$ & \\
\hline $\begin{array}{l}\text { O incêndio da casa, os furtos e as } \\
\text { acusações }\end{array}$ & Três (3) sequências & & $\mathrm{X}$ & $\mathrm{X}$ \\
\hline $\begin{array}{l}\text { O motivo de o companheiro de } \mathrm{d} \text {. } \\
\text { Arminda ter batido em Vitor }\end{array}$ & Uma (1) sequência & & $\mathrm{X}$ & \\
\hline $\begin{array}{l}\text { O conflito e as brigas entre Rui e a } \\
\text { família de Arminda }\end{array}$ & Duas (2) sequências & $\mathrm{X}$ & & $\mathrm{X}$ \\
\hline $\begin{array}{l}\text { O comportamento agressivo de } \\
\text { Arminda }\end{array}$ & Duas (2) sequências & & $\mathrm{X}$ & \\
\hline $\begin{array}{l}\text { O roubo do celular e a defesa } \\
\text { contra a agressão sofrida por } \\
\text { Arminda }\end{array}$ & Uma (1) sequência & & $\mathrm{X}$ & \\
\hline O emprego de Rui & Uma (1) sequência & $\mathrm{X}$ & & \\
\hline O comportamento violento de Rui & Quatro (4) sequências & $\mathrm{X}$ & & $\mathrm{X}$ \\
\hline $\begin{array}{l}\text { As ocorrências realizadas contra } \\
\text { Rui }\end{array}$ & Uma (1) sequência & $\mathrm{X}$ & & \\
\hline A carta escrita pela filha do casal & Uma (1) sequência & & & $\mathrm{X}$ \\
\hline A família de Rui & Uma (1) sequência & & & $\mathrm{X}$ \\
\hline $\begin{array}{l}\text { O envolvimento constante da } \\
\text { polícia na vida familiar }\end{array}$ & Duas (2) sequências & & & $\mathrm{X}$ \\
\hline
\end{tabular}

Fonte: elaborado pelos autores com base nos dados pertencentes ao grupo de pesquisa. 
Embora Sônia seja a participante a dar início a sequências conversacionais por mais vezes nesta fase da interação, Rui e Arminda têm a oportunidade de apresentar suas demandas tópicas nas duas entrevistas analisadas com mais frequência do que em outras fases encontradas.

Conforme discutido anteriormente, as atividades profissionais, tais como a consulta médica e a mediação, apresentam momentos em que os profissionais e os participantes realizam ações discursivas específicas, pertinentes a um dado momento da interação. Entendemos a fase "historiando o conflito" como o momento em que os participantes da atividade de pré-mediação conseguem colocar para a mediadora os motivos os quais deram início aos conflitos do ex-casal. A partir dessas versões narradas em entrevistas em separado com a mediadora, Sônia, por vezes, investiga com um participante aquilo que foi construído pelo outro.

A partir do exposto, podemos perceber a relevância dessa fase da interação para o fazer da mediação, visto que nela os participantes, mais do que respondendo questões elaboradas por Sônia, estão demonstrando o que para eles é relevante enquanto pai/mãe e homem/mulher, o que possibilita ao profissional de mediação ter a percepção do que deve ser debatido e o que deve ser evitado para que seja possível chegar ao acordo entre as partes ou, ao menos, tornar possível que aquelas pessoas, que precisam conviver e criar seus filhos, tenham um relacionamento mais harmonioso e maduro.

\section{Apontamentos}

Os dados apresentados retratam um caso de mediação judicial em Vara da Família do ano de 2008. Embora já houvesse na época discussões acerca da necessidade da mediação como forma de desobstruir o sistema jurídico brasileiro, principal motivo para a ampliação das formas alternativas de resolução de conflito, a mediação aqui estudada é fruto da crença da mediadora do caso no modelo transformador de mediação. Sua formação em Serviço Social e atuação em uma Vara da Família, juntamente com o seu conhecimento na área do direito, levaram-na ao exercício desse trabalho mais complexo e completo quanto à busca da transformação das relações familiares e da mudança na comunicação entre partes em desacordo. Não queremos, com isso, defender nem exaltar a mediadora, mas discutir o espaço dado atualmente, por meio da Lei da Mediação, ao efetivo empoderamento e exercício do protagonismo na vida dos envolvidos, tal como postulam os manuais de direito. 
De acordo com Barbosa (2014), a mediação - diferentemente das outras formas de resolução de conflitos, tal como a conciliação, por exemplo - atua na transformação da comunicação entre os sujeitos em conflito, e não na busca por um acordo. Tal premissa questiona o atual modelo de mediação adotado no sistema judiciário brasileiro, voltado unicamente para a minimização da morosidade da Justiça. Sim, sabemos que há pressa para que os direitos dos sujeitos sejam restabelecidos; contudo, a mediação propõe-se a prevenção de conflitos, extremamente necessária em relações contínuas envolvendo crianças. Defende-se, portanto, dentro de uma tendência no Direito brasileiro de minimização da interferência do Estado na vida do cidadão, que a mediação, conforme apontado por Barbosa (2014), é o espaço pedagógico para que o sujeito se torne protagonista de suas decisões e possa, com isso, lidar com os conflitos que surgirem ao longo de sua vida social e familiar.

A título de esclarecimento, no caso em estudo os participantes não deram continuidade ao processo judicial. Ao final do estudo de caso, Rui e Arminda decidiram tentar reatar o relacionamento. Desse modo, para a Justiça, esse caso é um exemplo malsucedido de mediação, pelo fato de não ter chegado ao acordo. No entanto, quando pensamos na restauração de relações, na reaproximação familiar, na convivência dos filhos com seus pais e, sobretudo, no fato de os participantes poderem escolher o que querem fazer com sua vida, a concepção do que seja o sucesso de uma mediação passa a ser outra.

Diante de tais reflexões, ratifica-se o lugar da pesquisa em Linguística Aplicada para a melhor compreensão das situações institucionais de uso da linguagem. No cenário jurídico, os conceitos e discussões embasadas em dados reais de fala-em-interação acerca das formulações e reformulações e da construção conjunta das narrativas demonstram como os sujeitos agem no mundo, construindo sua vida por meio da linguagem. Além disso, o estudo sobre as fases da entrevista de mediação fornece aos manuais sobre o tema subsídios para que essa atividade seja ressignificada a partir da compreensão dos discursos e objetivos de cada fase.

No todo, este artigo reforça a posição de Garcia (2010, p. 10), segundo a qual "precisamos prestar mais atenção às técnicas e estratégias interacionais usadas pelos disputantes", além de focar a atenção no que o mediador faz, para estudarmos melhor a competência interacional na mediação como um todo. 


\section{Referências}

AUSTIN, J. L. How to do things with words. Oxford: Clarendon, 1962.

BARBOSA, A. A. Guarda compartilhada e mediação familiar: uma parceria necessária. Revista Nacional de Direito de Família e Sucessões, Porto Alegre, v. 1, p. 2036, 2014.

BRASIL. Lei no 13.140, de 26 de junho de 2015. Diário Oficial da União, Brasília, DF, 29 jun. 2015.

BECKER, L. A. O mito da nentralidade do juiz:1995. Disponível em: < http://www. buscalegis.ufsc.br/revistas/files/anexos/16673-16674-1-PB.htm>. Acesso em: 25 abr. 2016.

BERGER, P.; LUCKMANN, T. A construção social da realidade: tratado de sociologia do conhecimento. Rio de Janeiro: Vozes, 1978.

BILMES, J. Occasioned semantics: a systematic approach to meaning in talk. Human Studies, v. 34, n. 2, p. 129-153, 2011.

CLARK, J.; MISHLER, E. Prestando atenção às histórias dos pacientes: o reenquadre da tarefa clínica. In: RIBEIRO, B. T.; LIMA, C. C.; DANTAS, M. T. L. (Org.). Narrativa, identidade e clinica. Rio de Janeiro: Ipub, 2001. p. 11-53.

DENZIN, N.; LINCOLN, Y. The discipline and practice of qualitative research. In: DENZIN, N.; LINCOLN, Y. The Sage Handbook of qualitative research. Thousand Oaks: Sage Publications, 2000. p. 1-27.

DREW, P.; HERITAGE, J. Talk at work: interaction in institutional settings. Cambridge: Cambridge University Press, 1992.

ENFIELD, N. J. Relationship thinking. Oxford: Oxford University Press, 2013.

GARCIA, A. C. The role of interactional competence in mediation. Conflict Resolution Quarterly, v. 28, n. 2, p. 205-228, 2010.

GARFINKEL, H. Studies in Ethnomethodology. Cambridge: Polity Press, 1967.

GARFINKEL, H.; SACKS, H. On formal structures of practical actions. In: McKINNEY, J. C.; TERYAKIAN, E. A. (Ed.). Theoretical Sociology. New York: Appleton-Century-Crofts, 1970. p. 160-193.

GOFFMAN, E. Footing. In: RIBEIRO, B. T.; GARCEZ, P. M. (Org.). Sociolinguística interacional. São Paulo: Loyola, 2002. p. 107-148.

GREATBATCH, D.; DINGWALL, R. The interactive construction of interventions by divorce mediators. In: FOLGER, J. P.; JONES, T. S. (Ed.). New directions in mediation: communication research and perspectives. Thousand Oaks: Sage Publications, 1994. p. 84-109. 
GRIMSHAW, A. Introduction. In: GRIMSHAW, A. (Ed.). Conflict talk: sociolinguistics investigation of arguments in conversation. Cambridge: Cambridge University Press, 1990. p. 1-20.

GUMPERZ, J. Convenções de contextualização. In: RIBEIRO, B. T.; GARCEZ, P. M. (Org.). Sociolinguística Interacional. 2. ed. Rio de Janeiro: Loyola, 2002. p.149-182. HERITAGE, J.; WATSON, D. R. Formulations as conversational objects. In.: PASATHAS, G. (Ed.). Everyday language. New York: Irvington, 1979. p. 123-162. HERITAGE, J.; WATSON, D. R. Aspect of the properties of formulations in natural conversations: some instances analysed. Semiotica, v. 30, n. 3-4, p. 245-262, 1980.

HUTCHBY, Y. Active listening: formulations and the elicitation of feelings-talk in child counseling. Research on Language and Social Interaction, v. 38, n. 3, p. 303-329, 2005.

LABOV, W. The transformation of experience in narrative syntax. In: LABOV, W. Language in the inner city: studies in the black English vernacular. Philadelphia: University of Pennsylvania Press, 1972. p. 354-397.

MILES, M. B.; HUBERMAN, A. M. Qualitative data analysis. London: Sage Publications, 1994.

MISHLER, E. G. The discourse of medicine: dialectics of medical interviews. Norwood: Ablex, 1984.

MISHLER, E. G. Research interviewing: context and narrative. Cambridge: Harvard University Press, 1986.

MISHLER, E. G. Work, identity and narrative: an artist-craftsman's story. In: ROSENWALD, G. C.; OCHBERG, R. L. (Ed.). Storied lives: the cultural politics of self-understanding. New York: Yale University Press, 1992.

MISHLER. E. Narrative accounts in clinical and research interviews. In: GUNNARSON, B. L.; LINELL, P.; NORDBERG, B. (Ed.) The construction of professional discourse. London: Longman, 1995. p.151-172.

MISHLER. E. Narrativa e identidade: a mão dupla do tempo. In: MOITA LOPES, L. P.; BASTOS, L. C. (Org.). Identidades: recortes multi e interdisciplinares. Campinas: Mercado de Letras, 2002. p. 97-119.

MOITA LOPES, L. P. Pesquisa interpretativista em Linguística Aplicada: a linguagem como condição e solução. Delta, v. 10, n. 2, p. 329-383, 1994.

SACKS, H.; SCHEGLOFF, E. A.; JEFFERSON, G. Sistemática elementar para a organização da tomada de turnos para a conversa. Revista Veredas de Estudos Linguisticos, v. 7, n. 2, p. 1-67, 2003. 
SCHEGLOFF, E. Discourse as interactional achievement III: the omni relevance of action. Research on Language and Social Interaction, v. 28, n. 3, p. 185-211, 1995.

SPENGER, F. M. Mediação enquanto política pública: a teoria, a prática e o projeto de lei. Santa Cruz do Sul: Edunisc, 2010.

TANNEN, D.; WALLAT, C. Enquadres interativos e esquemas de conhecimento em interação: exemplos de um exame/consulta médica. In: RIBEIRO, B. T.; GARCEZ, P. M. (Org.). Sociolinguística interacional. São Paulo: Loyola, 2002. p. 183214.

TEN HAVE, P. Doing conversation analysis: a practical guide. London: Sage, 1999.

VASCONCELOS, C. E. Mediação de conflitos e práticas restaurativas: modelos, processos, ética e aplicações. São Paulo: Método, 2006.

Data de submissão: 15/01/2017. Data de aprovação: 12/06/2017. 